\author{
Facultad de Medicina San Fernando \\ Universidad Nacional Mayor de San Marcos \\ Anales de la Facultad de Medicina
}

\title{
Declaración jurada de autoría y autorización para la publicación del artículo científico
}

Fecha:

Titulo:

DECLARACIÓN:

- Garantizo que el artículo que remito es un documento original y no ha sido publicado, total ni parcialmente, en otra revista científica biomédica, salvo en forma de resumen o tesis (en cuyo caso adjunto copia del resumen o carátula de la tesis).

- $\quad$ Si el artículo hubiera sido publicado previamente, adjunto la autorización original de la Revista donde se realizó la publicación primaria, de manera que pueda ser publicada en la Revista Anales de la Facultad de Medicina.

- Certifico que he contribuido directamente al contenido intelectual de este manuscrito, a la génesis y análisis de sus datos, por lo cual estoy en condiciones de hacerme públicamente responsable de él.

- En caso que el artículo fuese aprobado para su publicación en la Revista Anales de la Facultad de Medicina, cedo mis derechos patrimoniales y autorizo a la Facultad de Medicina San Fernando, de la Universidad Nacional Mayor de San Marcos, la publicación y divulgación del documento en las condiciones, procedimientos y medios que disponga la Facultad.

- No recibiré regalías ni otra compensación monetaria de parte de la Facultad de Medicina San Fernando por la publicación del artículo en la Revista Anales de la Facultad de Medicina.

- No he incurrido en fraude científico, plagio o vicios de autoría; en caso contrario, eximo de toda responsabilidad a la Revista Anales de la Facultad de Medicina y a la Facultad de Medicina San Fernando y me declaro como el único responsable.

- Adjunto a mi firma, incluyo cuál fue mi participación (y las de mis coautores) en la elaboración del artículo que presento para publicar a la Revista Anales de la Facultad de Medicina (Según tabla de códigos de participación).

Firma

Firma

Nombre:

Fecha:

DNI:

Código de participación:
Nombre:

Fecha:

DNI:

Código de participación: 
Firma

\section{Nombre:}

Fecha:

DNI:

Código de participación:

Firma

\section{Nombre:}

Fecha:

DNI:

Código de participación:

Firma

\section{Nombre:}

Fecha:

DNI:

Código de participación:
Firma

\section{Nombre:}

Fecha:

DNI:

Código de participación:

Firma

\section{Nombre:}

Fecha:

DNI:

Código de participación:

Firma

\section{Nombre:}

Fecha:

DNI:

Código de participación:

TABLA: CÓDIGOS DE PARTICIPACIÓN
a. Concepción y diseño del trabajo.
b. Recolección / obtención de resultados.
c. Análisis e interpretación de datos.
d. Redacción del manuscrito.
e. Revisión crítica del manuscrito.
f. Aprobación de su versión final.

g. Aporte de pacientes o material de estudio.

h. Obtención de financiamiento.

i. Asesoría estadística.

j. Asesoría técnica o administrativa.

k. Otras contribuciones (definir). 